\title{
外乱推定による連続時間モデル予測制御の オフセット補償*
}

櫻井 優太 ${ }^{\dagger} \cdot$ 大塚 敏之†

\author{
Offset Compensation of Continuous Time Model Predictive \\ Control by Disturbance Estimation*
}

Yuta SAKURAI $^{\dagger}$ and Toshiyuki OHtsuka ${ }^{\dagger}$

\begin{abstract}
In this paper, an offset compensation method for a continuous-time model predictive control (MPC) is proposed. To achieve offset-free control, additional disturbance states are introduced and the target for MPC is modified based on the estimate of disturbances. The property of steadystate deviation depends on the dimension of the additional disturbance states. An algorithm has already been proposed for discrete-time MPC to achieve zero offset when the model is augmented by disturbance states of the same dimension as tracked variables. We extend this algorithm to continuous-time MPC. A simulation result with the proposed algorithm for a nonlinear tank system is shown.
\end{abstract}

\section{1.はじめに}

モデル予測制御 (MPC) は , 動的モデルに基づき各時 刻で有限時間未来までの応答を最適化する制御手法であ る。制約を容易に扱うことが可能なため，近年，PID制 御に変わる高度な制御手法としてプロセス制御分野への 導入が盛んである [1] . 最適制御問題の評価区間が時間と ともに移動していることになるので, Receding Horizon 制御 ( $\mathrm{RH}$ 制御) ともよばれる $[2]$.

プロセス制御分野に限らず, 未知外乱が存在する場合 や，モデル化誤差が存在する場合，フィードバック制御 系に定常偏差が生じてしまうことがあるが，PID 制御に おいては積分動作によってこれを除去することができる． また， MPCにおいては，仮想外乱を新たな状態とみな してモデルに組み込むことで除去できる．

$\mathrm{MPC}$ は , サンプリング時間ごとに計画問題を解く必 要があり計算量が非常に多い.MPC の定常偏差除去の 手法においては, 外乱を新たな状態とみなすことで状態 変数が増え, 最適制御問題はより複雑となる. 光こでモ デルに組み込む外乱は少ないほうがよい. 従来, 定常偏

* 原稿受付 2011 年 10 月 7 日

$\dagger$ 大阪大学 大学院 基礎工学研究科 Graduate School of Engineering Science, Osaka University; 1-3 Machikaneyamacho, Toyonaka city, Osaka 560-8531, JAPAN

Key Words: offset compensation, disturbance estimation, model predictive control.
差を除去するためには, 出力と同次元の外乱をモデルに 組み込む必要があった [4]. 弚れに対し Maeder らは, 離 散時間 MPC において定常偏差なしで追従したい制御変 数と同次元の外乱のみの導入でオフセットを補償できる アルゴリズムを導いた [5]. 本研究では，これを連続時 間 MPCに拡張することを目的とし，非線形システムへ 適用した場合の特性を検討する . 連続時間 MPCにおい ては離散時間 MPC の場合と異なり, 評価区間上の時間 軸と実時間の時間軸でサンプリング周期を独立に選ぶここ とができるという利点がある．すなわち，制御系を設計 する段階でサンプリング周期を考慮する必要がない．ま た，連続時間 MPCにおける最適化計算を高速で行うア ルゴリズムが存在するため，光れを利用することもでき る $[2,3]$.

産業プロセス制御において,プラントは非線形なもの が非常に多い. 本研究では, 線形モデルを用いて MPC を定式化するが, 定常偏差が問題となるのは定常状態に おいてであり, 非線形プラントにおいても定常状態付近 では線形近似することができるため, 本研究の結果を適 用することができる. 并の有効性については数值シミュ レーションによって確認する．仮に, 定常状態から離れ た点での性能劣化が無視できない場合，たとえば，定常 状態に到達するまでは通常の非線形 MPC を用い，定常 状態に到達後に制御方法を本研究の方法に切り替えるこ とが考えられる . 


\section{2. 問題設定}

\section{1 プラントとモデル}

\section{1 .1 プラント}

連続時間の時不変システム

$$
\left\{\begin{array}{l}
\dot{x}_{p}(t)=f\left(x_{p}(t), u(t)\right) \\
y_{p}(t)=g\left(x_{p}(t)\right) \\
z(t)=H y_{p}(t)
\end{array}\right.
$$

を考える．ここで， $x_{p}(t) \in \mathbf{R}^{n}, u(t) \in \mathbf{R}^{m}, y_{p}(t) \in \mathbf{R}^{p}$ は光れ光れプラントの状態，入力，観測出力である．ま た， $z(t) \in \mathbf{R}^{r}$ は制御出力であり，観測出力の線形結合 で表される．一般性を失うことなく，行列 $H$ は行フル ランクであるとする . 拘束条件は

$$
E_{1} x_{p}(t)+E_{2} u(t) \leq M
$$

とし, 定常状態において拘束はアクティブでないものと する．また， $r(t) \in \mathbf{R}^{r}$ は一定值に収束する参照信号と し , $z(t)$ が $r(t)$ に追従することを制御目標とする .

2.1.2 制御対象のモデル

$\mathrm{MPC}$ では (1) 式に対し，次の線形時不変システム

$$
\left\{\begin{array}{l}
\dot{x}(t)=A x(t)+B u(t) \\
y(t)=C x(t)
\end{array}\right.
$$

を用いる.ここで $x(t) \in \mathbf{R}^{n}, u(t) \in \mathbf{R}^{m}, y(t) \in \mathbf{R}^{p}$ は 弚れ光れ，状態，入力，出力であり，対 $(A, B)$ は可制 御，対 $(C, A)$ は可観測であるとし,さらに， $C$ は行フ ルランクであるとする

\subsection{3 拡大モデル}

制御対象のモデル $(3)$ は , プラントとの不整合を捉え るために仮想的な外乱を導入したモデル (以下 , 拡大モ デル) に拡張される .ここでは参考文献 [4] のモデルに 従う.

$$
\left\{\begin{array}{l}
{\left[\begin{array}{l}
\dot{x}(t) \\
\dot{d}(t)
\end{array}\right]=\underbrace{\left[\begin{array}{cc}
A & B_{d} \\
O & O
\end{array}\right]}_{A_{m}}\left[\begin{array}{l}
x(t) \\
d(t)
\end{array}\right]+\underbrace{\left[\begin{array}{c}
B \\
0
\end{array}\right]}_{B_{m}} u(t)} \\
y(t)=\underbrace{\left[\begin{array}{cc}
C & \left.C_{d}\right]
\end{array}\right]}_{C_{m}}\left[\begin{array}{l}
x(t) \\
d(t)
\end{array}\right]
\end{array}\right.
$$

ここで， $d(t) \in \mathbf{R}^{n_{d}}$ は未知外乱であり，オブザーバに よって, 状態と外乱の両方を推定することを考える .

次の命題は , 拡大モデル (4) が可観測性であるための 必要十分条件を与えており, 外乱モデルの $B_{d}, C_{d}$ の選 び方を制限する。

【命題 1】拡大モデル (4) が可観測であるための必要 十分条件は, 対 $(C, A)$ が可観測かつ

$$
\left[\begin{array}{ll}
A & B_{d} \\
C & C_{d}
\end{array}\right]
$$

が列フルランクであることである .

(証明) $\mathrm{PBH}$ (Popov-Belevitch-Hautus) テストから， (4) 式のシステムが可観測であるための必要十分条件は, 任意の $\lambda$ に対し，

$$
\left[\begin{array}{cc}
A-\lambda I & B_{d} \\
O & -\lambda I \\
C & C_{d}
\end{array}\right]
$$

が列フルランクであることである .

再び， $\mathrm{PBH}$ テストから，第 1 列が線形独立であるの は, 対 $(C, A)$ が可観測であるとき，かつ光のときに限 る. 第 2 列は $\lambda=0$ である場合を除いて第 1 列に対して 線形独立である . すなわち, 拡大モデルに対する $\mathrm{PBH}$ テストは $\lambda=0$ のときのみチェックされる必要があり，光 れは (5) 式となる .

(注意 1 ) 命題 1 より拡大モデルが可観測であるため には $n_{d} \leq p$ でなければならないことに注意する . 次の系が命題 1 より直接導かれる.

【系 1】拡大モデル $(4)$ において,$n_{d}=p$ かつ $C_{d}=I$ のとき, 可観測であるための必要十分条件は, 対 $(C, A)$ が可観測かつ

$$
\operatorname{det}\left[\begin{array}{cc}
A & B_{d} \\
C & I
\end{array}\right]=\operatorname{det}\left(A-B_{d} C\right) \neq 0
$$

が成り立つことである .

(注意 2) もし制御対象が積分器を持たないならば, 行 列 $A$ は 0 を固有值に持たず, $\operatorname{det} A \neq 0$ より $B_{d}=0$ と 選ぶことができる．これは，観測外乱のみを考えること に相当する．もし，制御対象が積分器を持つならば， $B_{d}$ は $\operatorname{det}\left(A-B_{d} C\right) \neq 0$ となるよう選ばなければならない . 以下で, 状態方程式にのみ外乱を導入するモデル (状 態外乱モデル) と, 観測出力のみに外乱を導入するモデ ル (出力外乱モデル) の等価性を証明する [6]. まず，相 似変換

$$
T=\left[\begin{array}{cc}
I & -T_{12} \\
O & I
\end{array}\right]
$$

を導入する．すると，変換されたシステム行列は

$$
\begin{aligned}
T A_{m} T^{-1} & =\left[\begin{array}{cc}
A & A T_{12}+B_{d} \\
O & O
\end{array}\right] \\
C_{m} T^{-1} & =\left[\begin{array}{ll}
C & C T_{12}+C_{d}
\end{array}\right]
\end{aligned}
$$

となる . 出力外乱モデル $\left(C_{d} \neq 0, B_{d}=0\right)$ が , 状態外乱 モデルへ変形されうることは

$$
C T_{12}=-C_{d}
$$

を $T_{12}$ について解くことによって簡単にわかる.$C$ が 行フルランクなので, 解は常に存在する .

逆に, 状態外乱モデル $\left(C_{d}=0, B_{d} \neq 0\right)$ は， 


$$
A T_{12}=-B_{d}
$$

を $T_{12}$ について解くことによって , 純粋な出力外乱モデ ルへ変形されうる. 解 $T_{12}$ が存在するための必要十分 条件は, $\operatorname{span}\left(-B_{d}\right) \subset \operatorname{span}(A)$ であることであり，こ れは原点に固有值を持たないプラントでは明らかに真と なる .

\subsection{4 プラントとモデルに関する補足}

プラントとモデルが共に定常状態であれば，弚の出力 の差は一定であり，一定值外乱で補償できる．本研究で は, プラントと拡大モデルの出力を等しいとみなして仮 想外乱を導入した .とくに，一般の非線形システム $(1)$ 式に対して , 線形モデルを用いて定式化しており，さら に，モデルプラントミスマッチを想定する場合，モデル が定常状態に到達していても，プラントが定常状態と なっていることは保証されない．次の命題は，プラント とモデルが共に定常状態となりうることを保証するため の条件を提示している.

【命題 2】任意の可能な $g\left(x_{p, \infty}\right)$ に対し , 次の 3 式 を満たす $x_{\infty}, u_{\infty}, d_{\infty}, x_{p, \infty}$ が存在すれば, 閉ループ 系においてモデルとプラントは共に定常状態になりうる . ここで , 添字 $\infty$ は定常状態での値を表す .

$$
\begin{aligned}
& 0=A x_{\infty}+B u_{\infty}+B_{d} d_{\infty} \\
& 0=f\left(x_{p, \infty}, u_{\infty}\right) \\
& C x_{\infty}+C_{d} d_{\infty}=g\left(x_{p, \infty}\right)
\end{aligned}
$$

(証明) (8), (9) 式はとれ光れ，モデルとプラントが共 通の一定値入力 $u_{\infty}$ で定常状態となることを表し，(10) 式は定常状態での拡大モデルとプラントの出力が等し いことを表す．この 3 式が同時に成り立つことは， $x_{\infty}$, $u_{\infty}, d_{\infty}, x_{p, \infty}$ で, モデルとプラントが共に定常状態と なっていることを示す．

(注意 3) (8), (10) 式をまとめると

$$
\left[\begin{array}{ll}
A & B_{d} \\
C & C_{d}
\end{array}\right]\left[\begin{array}{l}
x_{\infty} \\
d_{\infty}
\end{array}\right]=\left[\begin{array}{c}
-B u_{\infty} \\
g\left(x_{p, \infty}\right)
\end{array}\right]
$$

となる . 拡大モデルが可観測であれば , 命題 1 によって 左辺の行列は列フルランクなので, (11) 式を $x_{\infty}, d_{\infty}$ について解く場合, 弚れは唯一解となる .

(注意 4) 拡大モデルが可観測で，(8) (10) 式の解が 存在する場合, モデルが定常状態ならば , プラントの出 力も一定となる .

\section{2 オブザーバの設計}

オブザーバは次の式で構成される .

$$
\begin{aligned}
{\left[\begin{array}{c}
\dot{\hat{x}}(t) \\
\dot{\hat{d}}(t)
\end{array}\right]=} & {\left[\begin{array}{cc}
A & B_{d} \\
O & O
\end{array}\right]\left[\begin{array}{c}
\hat{x}(t) \\
\hat{d}(t)
\end{array}\right]+\left[\begin{array}{c}
B \\
0
\end{array}\right] u(t) } \\
& +\left[\begin{array}{c}
L_{x} \\
L_{d}
\end{array}\right]\left(-y_{p}(t)+C \hat{x}(t)+C_{d} \hat{d}(t)\right)
\end{aligned}
$$

ここで， $L_{x}$ と $L_{d}$ はオブザーバが漸近安定となるよう 選ばれる . オブザーバで推定された状態と外乱の推定值 は, MPCの初期化と目標状態の導出機構 (Steady State Target Optimizer; SSTO)に用いられる .

次の補題 1 は, オブザーバが安定であるための必要条 件であり，命題 3 と定理 1 の証明に用いられる .

【補題 1】オブザーバ(12)が安定ならば, $\operatorname{rank} L_{d}=$ $n_{d}$ が成り立つ.

(証明) (12) 式を変形すると

$$
\begin{aligned}
{\left[\begin{array}{c}
\dot{\hat{x}}(t) \\
\hat{\hat{d}}(t)
\end{array}\right]=} & {\left[\begin{array}{cc}
A+L_{x} C & B_{d}+L_{x} C_{d} \\
L_{d} C & L_{d} C_{d}
\end{array}\right]\left[\begin{array}{l}
\hat{x}(t) \\
\hat{d}(t)
\end{array}\right] } \\
& +\left[\begin{array}{c}
B \\
0
\end{array}\right] u(t)-\left[\begin{array}{c}
L_{x} \\
L_{d}
\end{array}\right] y_{p}(t)
\end{aligned}
$$

となる . オブザーバの漸近安定性より原点に極を持たな いので ,

$$
\operatorname{det}\left[\begin{array}{cc}
A+L_{x} C & B_{d}+L_{x} C_{d} \\
L_{d} C & L_{d} C_{d}
\end{array}\right] \neq 0
$$

が成り立つ . (14) 式が成り立つためには, 行列の第 2 行 は, 行フルランクでなければならない . 谷のための必要 条件は， $L_{d}$ が行フルランクであることである .

\section{$2.3 \mathrm{MPC}$ の設計}

\subsubsection{SSTO の設計}

SSTO とは, MPC において, 設定された指令値に到 達するために状態と入力が到達すべき目標値を導出する 機構のことである .ここで, 設定された指令值とは, 参 照軌道 $r(t)$ のことを指す . SSTO を設計するに当たって 次の命題を示す.

【命題 3】 $n_{d}=p$ と選び，オブザーバ $(12)$ が安定な らば , オブザーバ $(12)$ の定常状態は

$$
\left[\begin{array}{ll}
A & B \\
C & O
\end{array}\right]\left[\begin{array}{l}
\hat{x}_{\infty} \\
u_{\infty}
\end{array}\right]=\left[\begin{array}{c}
-B_{d} \hat{d}_{\infty} \\
y_{p, \infty}-C_{d} \hat{d}_{\infty}
\end{array}\right]
$$

を満たす.ここで, $y_{p, \infty}$ と $u_{\infty}$ は, 乥れ光れ定常状態 での出力, 定常状態でのシステム $(1)$ への入力であり, $\hat{x}_{\infty}$ と $\hat{d}_{\infty}$ は, 弚れ光れオブザーバ $(12)$ から得られる定 常状態における状態の推定值と外乱の推定值である .

(証明) (12) 式より外乱の推定值 $\hat{d}$ は, $L_{d}\left(-y_{p, \infty}+\right.$ $\left.C \hat{x}_{\infty}+C_{d} \hat{d}_{\infty}\right)=0$ のときのみ収束するということに注 意する. 仮定より $L_{d}$ は正方行列で, 補題 1 より正則 であり, 定常状態でも正則なので, オブザーバの推定值 (12)は

$$
-y_{p, \infty}+C \hat{x}_{\infty}+C_{d} \hat{d}_{\infty}=0
$$

を満たす . (12), (16) 式から直接 $(15)$ 式が成り立つこと がわかる.

定常状態における制御出力と参照信号を, 弚れ光れ $z_{\infty}=H y_{p, \infty}, r_{\infty}$ と表す. 定常偏差ゼロは, $z_{\infty}=r_{\infty}$ 
を意味する.オブザーバの条件 $(15) よ り ，$ 定常状態にお いて , MPCは

$$
\left[\begin{array}{cc}
A & B \\
H C & 0
\end{array}\right]\left[\begin{array}{l}
x_{\infty} \\
u_{\infty}
\end{array}\right]=\left[\begin{array}{c}
-B_{d} \hat{d}_{\infty} \\
r_{\infty}-H C_{d} \hat{d}_{\infty}
\end{array}\right]
$$

を満たすべきとわかる .ここで， $x_{\infty}$ は定常状態での MPC の評価区間上の状態である . (17) 式より SSTO は 以下のように設計される .

$$
\left[\begin{array}{cc}
A & B \\
H C & 0
\end{array}\right]\left[\begin{array}{c}
\bar{x}_{t} \\
\bar{u}_{t}
\end{array}\right]=\left[\begin{array}{c}
-B_{d} \hat{d}(t) \\
r(t)-H C_{d} \hat{d}(t)
\end{array}\right]
$$

ここで, $\bar{x}_{t}, \bar{u}_{t}$ は時刻 $t$ での状態と入力の目標值である .

(注意 5) (17) 式より，任意の $\hat{d}_{\infty} と r_{\infty}$ に対して， $x_{\infty}$ と $u_{\infty}$ が存在するためには, 行列 $\left[\begin{array}{cc}A & B \\ H C & 0\end{array}\right]$ が行 フルランク，すなわち， $m \geq r$ でなければならない .

(注意 6) もし条件 $(18)$ から $\bar{x}_{t}$ と $\bar{u}_{t}$ が一意に決まら ないなら，(18) 式の制約のもと， $\bar{u}_{t}$ の大きさを最小化 するような最適化問題を解くことによって $\bar{x}_{t}$ と $\bar{u}_{t}$ を 決定することが考えられる .

\subsubsection{MPC の設計}

$\mathrm{MPC}$ は次のように設計される .

$$
\begin{aligned}
& \min _{u_{M}(\tau), t \leq \tau \leq t+T}\left\|x(t+T)-\bar{x}_{t}\right\|_{P}^{2} \\
& \quad+\int_{t}^{t+T}\left\{\left\|x(\tau)-\bar{x}_{t}\right\|_{Q}^{2}+\left\|u_{M}(\tau)-\bar{u}_{t}\right\|_{R}^{2}\right\} \mathrm{d} \tau
\end{aligned}
$$

sub. to $E_{1} x(\tau)+E_{2} u_{M}(\tau) \leq M, t \leq \tau \leq t+T$

$$
\begin{aligned}
& \dot{x}(\tau)=A x(\tau)+B u_{M}(\tau)+B_{d} d(\tau), t \leq \tau \leq t+T \\
& \dot{d}(\tau)=0, t \leq \tau \leq t+T \\
& x(t)=\hat{x}(t), d(t)=\hat{d}(t)
\end{aligned}
$$

ここで, $\|x\|_{M}^{2}=x^{\mathrm{T}} M x, Q \geq 0, R>0$ であり, $P$ は Riccati 方程式

$$
P A+A^{\mathrm{T}} P-P B R^{-1} B^{\mathrm{T}} P+Q=0
$$

の正定解とする . ただし , 評価関数における $\bar{x}_{t}$ と $\bar{u}_{t}$ は SSTO (18) 式で計算される . また, $\bar{x}_{t}$ と $\bar{u}_{t}$ は，時刻 $t$ のみに依存し，評価区間上では一定值であることに注意

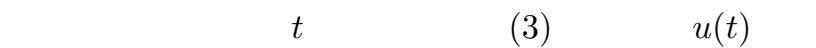
最適化問題 $(19)$ の最適化変数 $u_{M}(\tau)$ は区別することに も注意する。同樣に， $x(t)$ は時刻 $t$ での状態を表し ,一 方, 変数 $x(\tau)(t \leq \tau \leq t+T)$ は状態 $x(t)=\hat{x}(t)$ からス タートし, システム $(3)$ への入力 $u_{M}\left(\tau^{\prime}\right),\left(t \leq \tau^{\prime} \leq \tau\right)$ を 適用することによって得られる時刻 $\tau$ での予測状態を表 す. $u_{M}^{*}(\tau)(t \leq \tau \leq t+T)$ を(18), (19) 式の最適解とす ると, $u_{M}^{*}(\tau)$ の $\tau=t$ での值がシステム $(1)$ に適用され

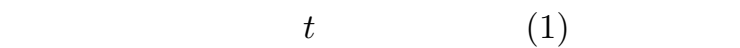

$$
u(t)=u_{M}^{*}(t)
$$

である

推定状態が $\hat{x}(t)$, 推定外乱が $\hat{d}(t)$ のとき, 制御則を $u_{M}^{*}(\hat{x}(t), \hat{d}(t), r(t))$ と表すものとすると, (18), (19) 式 の MPC, (12) 式のオブザーバで(1) 式のシステムを制御 することによって得られる閉ループ系は, 以下のように 表される .

$$
\begin{aligned}
\dot{x}(t)= & f\left(x(t), u_{M}^{*}(\hat{x}(t), \hat{d}(t), r(t))\right) \\
\dot{\hat{x}}(t)= & \left(A+L_{x} C\right) \hat{x}(t)+\left(B_{d}+L_{x} C_{d}\right) \hat{d}(t) \\
& +B u_{M}^{*}(\hat{x}(t), \hat{d}(t), r(t))-L_{x} y_{p}(t) \\
\dot{\hat{d}}(t)= & L_{d} C \hat{x}(t)+L_{d} C_{d} \hat{d}(t)-L_{d} y_{p}(t)
\end{aligned}
$$

(注意 7) MPC (19) では終端状態の重みに Riccati 方程式 (20) の正定解を用いているが，これに関しては 次の命題 4 を参照のこと.

【命題 4】 (18), (19) 式の MPC を考える . また, 定 常状態では拘束を受けないとする．すると定常状態では

$$
\delta u=K_{\mathrm{MPC}} \delta x
$$

となる .ここで, $\delta u=u_{\infty}-\bar{u}_{\infty}, \delta x=\hat{x}_{\infty}-\bar{x}_{\infty}, K_{\mathrm{MPC}}=$ $-R^{-1} B^{\mathrm{T}} P$ とした . $P$ は Riccati 方程式 $(20)$ の正定解 である. $u_{\infty}, \bar{u}_{\infty}, \hat{x}_{\infty}, \bar{x}_{\infty}$ は光れ光れ定常状態におけ

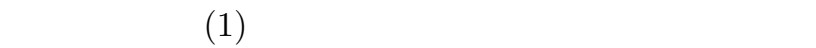
光の目標値である.

(証明) (18), (19) 式の MPC は, 目的関数が目標値 との偏差で構成されているので, $\delta x(\tau)=x(\tau)-\bar{x}_{t}$, $\delta u_{M}(\tau)=u_{M}(\tau)-\bar{u}_{t}$ と変数変換をした偏差系を考え る.評価区間上では外乱は一定なので, (18)式において外 乱推定值を評価区間での外乱に置き換えた式 $(\hat{d}(t)=d(\tau))$ を用いることで

$$
\begin{aligned}
H y(\tau)-r(t) & =H C x(\tau)+H C_{d} d(\tau)-r(t) \\
& =H C \delta x(\tau)+H C \bar{x}_{t}+H C_{d} d(\tau)-r(t) \\
& =H C \delta x(\tau)
\end{aligned}
$$

となることがわかる．つまり， $\delta x(\tau)$ を小さくするよう な評価関数を設定すれば, 制御出力が参照軌道に追従す ることを目的とした MPC が設計できる．また，ホライ ゾン内の時間軸 $\tau$ 上では $\dot{\bar{x}}_{t}=0$ なので, 状態方程式 (4) と $\hat{d}(t)=d(\tau)$ としたときの $(18)$ 式より，

$$
\begin{aligned}
\delta \dot{x}(\tau) & =\dot{x}(\tau)-\dot{\bar{x}}_{t} \\
& =A\left(\delta x(\tau)+\bar{x}_{t}\right)+B\left(\delta u_{M}(\tau)+\bar{u}_{t}\right)+B_{d} d(\tau) \\
& =A \delta x(\tau)+B \delta u_{M}(\tau)+A \bar{x}_{t}+B \bar{u}_{t}+B_{d} d(\tau) \\
& =A \delta x(\tau)+B \delta u_{M}(\tau)
\end{aligned}
$$

となる . すると , 偏差系の MPC は

$$
\begin{aligned}
\min _{\delta u_{M}(\tau), t \leq \tau \leq t+T} & \|\delta x(t+T)\|_{P}^{2} \\
& +\int_{t}^{t+T}\left\{\|\delta x(\tau)\|_{Q}^{2}+\left\|\delta u_{M}(\tau)\right\|_{R}^{2}\right\} \mathrm{d} \tau
\end{aligned}
$$


sub. to $\quad E_{1} \delta x(\tau)+E_{2} \delta u_{M}(\tau) \leq M^{\prime}$

$$
\begin{aligned}
& \delta \dot{x}(\tau)=A \delta x(\tau)+B \delta u_{M}(\tau), t \leq \tau \leq t+T \\
& \delta x(t)=\hat{x}(t)-\bar{x}_{t}
\end{aligned}
$$

と定式化できる．ここで， $M^{\prime}$ は $M$ とは異なる行列で ある .

(23) 式の MPC は区間 $[t, t+T]$ に関して最適化を行 うが , 終端条件を Riccati 方程式の解を用いて記述して いるため，区間 $[t+T, \infty)$ においても最適レギュレータ の意味で最適化されている．定常状態では $[t, \infty)$ で拘束 を受けない、したがって，最適制御は Riccati 方程式

$$
P A+A^{\mathrm{T}} P-P B R^{-1} B^{\mathrm{T}} P+Q=0
$$

の正定解 $P$ を用いて $\delta u_{M}^{*}(t)=-R^{-1} B^{\mathrm{T}} P \delta x(t)$ と書け る.よって,$K_{\mathrm{MPC}}=-R^{-1} B^{\mathrm{T}} P$ とおくと $\delta u_{M}^{*}(t)=$ $K_{\mathrm{MPC}} \delta x(t)$ となる .

定常状態では, $\delta u_{M}^{*}(t) \rightarrow u_{\infty}-\bar{u}_{\infty}=\delta u, \delta x(t) \rightarrow \hat{x}_{\infty}-$ $\bar{x}_{\infty}=\delta x$ が成り立つ.ゆえに， $\delta u=K_{\mathrm{MPC}} \delta x$ となる.

(注意 8) $U^{*}(t)=\left\{\delta u_{M}^{*}(\tau) \mid t \leq \tau \leq t+T\right\}$ を偏差系の $\operatorname{MPC}(23)$ の最適解とすると , システム (1) に実際に適 用される時刻 $t$ での入力は

$$
u(t)=\bar{u}_{t}+\delta u_{M}^{*}(t)
$$

である .

\section{4 全体の構成}

プラント，オブザーバ, MPC , SSTO を組み合わせ た全体の構成図はFig. 1 で表される．プラントは一般に 非線形であるのに対し，オブザーバと MPC は (線形) 拡大モデルを用いて設計される . モデル・プラントミス マッチが生じている場合，オブザーバで推定された状態 $\hat{x}$ はプラントの真の状態 $x$ とは異なることに注意する .

オブザーバは , プラントの入出力から拡大モデルにお ける状態と外乱の推定値を出し，SSTOは推定された外 乱を用いて設定値に対する状態の入力の目標値を計算す る.MPCでは，オブザーバから得られた推定值を初期 値とし，SSTOで計算された目標状態を状態と入力の目 標値とした最適化問題が解かれ，プラントへの入力が導 出される.

\section{3. 定常偏差ゼロのための条件と提案アル} ゴリズム

外乱状態の数 $n_{d}$ を観測出力の数 $p$ と等しくとると， (18), (19) 式のようにMPC を設計した場合，定常偏差が ゼロとなることが示される [4]．しかし，観測出力と同次 元の外乱を導入してしまうと MPC を解くうえで計算量 が増加してしまう可能性があり, オブザーバの計算量も 増加する . 光こで, 制御出力を参照信号に追従させると いう制御目標のもと，モデルに組み込む外乱の次元を観

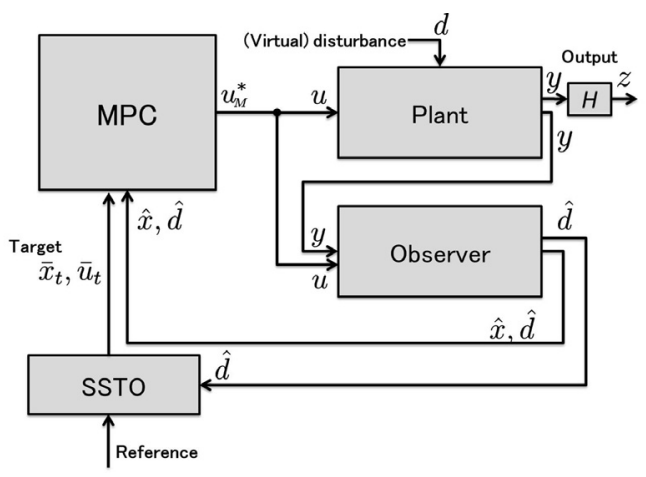

Fig. 1 Framework of the system

測出力より少なくすることを考える . 内部モデル原理か ら，定常偏差ゼロで追従されるべきあらゆる出力に対し， 少なくとも一つの外乱状態を加える必要があることは明 らかである.したがって, 加える外乱の数 $n_{d}$ を制御出 力の数 $r$ に等しくなるよう選ぶ.すなわち， $n_{d}=r<p$ である．一般にこの選び方では, 制御器を前章のように 設計すると, 命題 $\mathbf{3}$ が保たれないので, 定常偏差ゼロで の追従は保証されない . まず, 定常状態における追従エ ラーの特徵付けを行う．つぎに，定常偏差がゼロとなる 条件を導出し, 定常偏差ゼロが得られるようなオブザー バの構成方法を示す．

\section{1 定常偏差の特徵付け}

$n_{d}=p$ とは限らない一般の場合, 命題 $\mathbf{3}$ は次の命題 に置き換えられる．

【命題 5】 (12) 式のオブザーバの定常状態は

$$
\left[\begin{array}{cc}
A+L_{x} C & B \\
L_{d} C & 0
\end{array}\right]\left[\begin{array}{l}
\hat{x}_{\infty} \\
u_{\infty}
\end{array}\right]=\left[\begin{array}{c}
L_{x} y_{p, \infty}-\left(B_{d}+L_{x} C_{d}\right) \hat{d}_{\infty} \\
L_{d} y_{p, \infty}-L_{d} C_{d} \hat{d}_{\infty}
\end{array}\right]
$$

を満たす.ここで， $y_{p, \infty}$ と $u_{\infty}$ は, 弚れ午れシステム (1) における定常状態の観測出力 , 入力である . また $\hat{x}_{\infty}$ と $\hat{d}_{\infty}$ は，乥れ光れ定常状態において，オブザーバ(12) から得られる状態と外乱の推定值である .

(証明) (12) 式から定常状態で

$$
\begin{aligned}
& 0=A \hat{x}_{\infty}+B_{d} \hat{d}_{\infty}+B u_{\infty}+L_{x}\left(C \hat{x}_{\infty}+C_{d} \hat{d}_{\infty}-y_{p, \infty}\right) \\
& 0=L_{d}\left(-y_{p, \infty}+C \hat{x}_{\infty}+C_{d} \hat{d}_{\infty}\right)
\end{aligned}
$$

が成り立つ . (26) 式は $(27)$ 式から直接導くことができ る。

定常状態では拘束を受けないので, 命題 4 より, MPC コントローラ (19),(18) は

$$
u_{\infty}-\bar{u}_{\infty}=K_{\mathrm{MPC}}\left(\hat{x}_{\infty}-\bar{x}_{\infty}\right)
$$

を満たす . (18), (26), (28) 式を組み合わせ , 偏差方程式 $\epsilon=H y_{p, \infty}-r_{\infty}$ を用いることによって , オブザーバと 制御器の定常状態での值は次の方程式を満たすことがわ 
かる .

$$
M_{1} v+M_{2} \epsilon=0
$$

ここで，

$$
\begin{aligned}
& v=\left[\hat{x}_{\infty}^{\mathrm{T}} u_{\infty}^{\mathrm{T}} \bar{x}_{\infty}^{\mathrm{T}} \bar{u}_{\infty}^{\mathrm{T}} \hat{d}_{\infty}^{\mathrm{T}} y_{p, \infty}^{\mathrm{T}}\right]^{\mathrm{T}} \\
& M_{1}=\left[\begin{array}{cccccc}
A+L_{x} C & B & 0 & 0 & B_{d}+L_{x} C_{d}-L_{x} \\
L_{d} C & 0 & 0 & 0 & L_{d} C_{d} & -L_{d} \\
0 & 0 & A & B & B_{d} & 0 \\
0 & 0 & H C & 0 & H C_{d} & -H \\
K_{\mathrm{MPC}} & -I & -K_{\mathrm{MPC}} & I & 0 & 0
\end{array}\right] \\
& M_{2}=\left[\begin{array}{lllll}
0 & 0 & 0 & I & 0
\end{array}\right]^{\mathrm{T}}
\end{aligned}
$$

である .すべての可能な偏差の集合は , 部分空間 $\mathcal{K}:=$ $\left\{(v, \epsilon) \mid M_{1} v+M_{2} \epsilon=0\right\}$ の偏差 $\epsilon$ の空間への射影（これ を $\Pi_{\epsilon}(\mathcal{K})$ と表す) に属する .

次のアルゴリズムは , すべての可能な偏差 $\epsilon$ によって 張られる最小の部分空間 $\mathcal{H}:=\Pi_{\epsilon}(\mathcal{K}) \subset \mathbf{R}^{n_{d}}$ を決める標 準的な手順を示す $[5]$.

【アルゴリズム 1】（1) $\operatorname{rank}\left(M_{1}\right)=\operatorname{rank}\left(\left[M_{1}, M_{2}\right]\right)$ ならば， $\Pi_{\epsilon}(\mathcal{K})$ はフル次元である.すなわち， $\mathcal{H}=\mathbf{R}^{n_{d}}$ である .

(2) $\forall j\left(j=1,2, \ldots, n_{d}\right)$ に対し, $\operatorname{rank}\left(\left[M_{1} M_{2}^{<j>}\right]\right) \neq$ $\operatorname{rank}\left(\left[M_{1} M_{2}\right]\right)$ であれば，定常偏差は 0 であり， $\mathcal{H}=\{\mathbf{0}\}$ である.ただし， $M^{<j>}$ は行列 $M$ から 第 $j$ 列を除いた行列を表すものとする .

(3) 乥うでなければ， $N$ を $M_{1}^{\mathrm{T}} N=0$ を満たす行列と

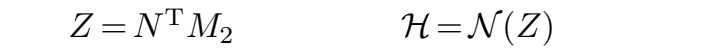
だし $\mathcal{N}(\cdot)$ は零空間を表す。

(注意 9) 定常偏差ゼロで MPC 制御器を構成するこ とは容易な問題ではない. 実際 $Z$ (すなわち $\mathcal{H}$ ) は $L_{x}$, $L_{d}, H, K_{\mathrm{MPC}}$ の関数である.

\section{2 定常偏差ゼロのための条件}

$e_{\infty}=y_{p, \infty}-C \hat{x}_{\infty}-C_{d} \hat{d}_{\infty}$ と定義することによって, (29)式は次のように書き換えられる .

$$
\tilde{M}_{1} \tilde{v}+M_{2} \epsilon=0
$$

ここで，

$$
\begin{aligned}
\tilde{v} & =\left[\hat{x}_{\infty}^{\mathrm{T}} u_{\infty}^{\mathrm{T}} \bar{x}_{\infty}^{\mathrm{T}} \bar{u}_{\infty}^{\mathrm{T}} \hat{d}_{\infty}^{\mathrm{T}} e_{\infty}^{\mathrm{T}}\right. \\
\tilde{M}_{1} & =\left[\begin{array}{cccccc}
A & B & 0 & 0 & B_{d} & -L_{x} \\
0 & 0 & 0 & 0 & 0 & -L_{d} \\
0 & 0 & A & B & B_{d} & 0 \\
-H C & 0 & H C & 0 & 0 & -H \\
K_{\mathrm{MPC}} & -I & -K_{\mathrm{MPC}} & I & 0 & 0
\end{array}\right]
\end{aligned}
$$

直接代入によって，(30) 式から次の式が得られる .

$$
\left[\begin{array}{c}
L_{d} \\
H\left(I+C\left(A+B K_{\mathrm{MPC}}\right)^{-1} L_{x}\right)
\end{array}\right] e_{\infty}=\left[\begin{array}{l}
0 \\
I
\end{array}\right] \epsilon
$$

(32) 式から，定常偏差ゼロを得るには，(32) 式を解 くことで求まるすべての $e_{\infty}$ で $\epsilon=0$ となるという条 件が満たされればよい，と結論づけることができる． この条件は， $L_{d} e_{\infty}=0$ が満たされるすべての $e_{\infty}$ で $H\left(I+C\left(A+B K_{\mathrm{MPC}}\right)^{-1} L_{x}\right) e_{\infty}=0$ となる, と言い換 えられる.このことは，次の零空間の条件に書き換えら れる 。

$$
\mathcal{N}\left(L_{d}\right) \subset \mathcal{N}\left(H\left(I+C\left(A+B K_{\mathrm{MPC}}\right)^{-1} L_{x}\right)\right)
$$

簡単のため, 次の記号

$$
\Phi=A+B K_{\mathrm{MPC}}
$$

を導入すると，制御出力が定常偏差ゼロを達成するため の十分条件は

$$
\mathcal{N}\left(L_{d}\right) \subset \mathcal{N}\left(H\left(I+C \Phi^{-1} L_{x}\right)\right)
$$

とかける .

\section{3 定常偏差ゼロの条件を満たすオブザーバゲ} インを求めるアルゴリズム

以下で, $n_{d}=r<p$ のとき, $(35)$ 式の条件を満たす $L_{x}, L_{d}$ の構成法を提案する.MPC は (18), (19) 式の ように定義されているとし，定常状態では，拘束がアク ティブでないとする.次の補題は, 定理 1 の証明に用 いる .

【補題 2】行列 $A \in \mathbf{R}^{n \times n}, B \in \mathbf{R}^{n \times n}, C \in \mathbf{R}^{n \times m}(n<$ $m)$ に対し，行列 $A$ が正則ならば，

$$
\mathcal{N}(A C) \subset \mathcal{N}(B C)
$$

が成り立つ。

(証明) $A$ が正則行列なので

$$
\begin{aligned}
\mathcal{N}(A C) & =\left\{x \in \mathbf{R}^{m} \mid A C x=0\right\} \\
& =\left\{x \in \mathbf{R}^{m} \mid C x=0\right\} \\
& \subset\left\{x \in \mathbf{R}^{m} \mid B C x=0\right\} \\
& =\mathcal{N}(B C)
\end{aligned}
$$

が成り立つ。

【定理 1】 $n_{d}=r$ とした拡大モデル (4)において，

$$
L=\left[\begin{array}{c}
L_{x} \\
L_{d}
\end{array}\right]=\left[\begin{array}{c}
\tilde{L}_{x} \\
0
\end{array}\right]+\left[\begin{array}{c}
\bar{L}_{x} \\
\bar{L}_{d}
\end{array}\right] \bar{H}
$$

という形のオブザーバゲインを用いる場合を考える .こ こで， $\bar{H}=H\left(I+C \Phi^{-1} \tilde{L}_{x}\right)$ である . 閉ループのオブ ザーバダイナミクス $A_{m}+L C_{m}$ は安定であるとする . さらに, 閉ループ系は定常状態に到達するとする .する と制御器 (19)〜 (21) は偏差のない追従特性をもつ.

(証明)（35) 式の両辺に (36) 式を代入することにより，

$$
\begin{aligned}
& ((35) \text { 式の左辺 })=\mathcal{N}\left(\bar{L}_{d} \bar{H}\right) \\
& ((35) \text { 式の右辺 })=\mathcal{N}\left(H\left(I+C \Phi^{-1}\left(\tilde{L}_{x}+\bar{L}_{x} \bar{H}\right)\right)\right)
\end{aligned}
$$




$$
\begin{aligned}
& =\mathcal{N}\left(H\left(I+C \Phi^{-1} \tilde{L}_{x}+C \Phi^{-1} \bar{L}_{x} \bar{H}\right)\right) \\
& =\mathcal{N}\left(\bar{H}+H C \Phi^{-1} \bar{L}_{x} \bar{H}\right) \\
& =\mathcal{N}\left(\left(I+H C \Phi^{-1} \bar{L}_{x}\right) \bar{H}\right)
\end{aligned}
$$

となる.補題 1 で示したように, $L_{d}=\overline{L_{d}} \bar{H}$ は行フルラ ンク , すなわち $\overline{L_{d}}$ は行フルランクである .いま $n_{d}=r$ なので， $\bar{L}_{d}$ は正方行列であり，すなわち正則行列であ る.補題 2 より.(35) 式の定常偏差ゼ口の条件が成り立 つことがわかる .

定理 1 に基づくオブザーバの設計法は以下のようにま とめられる .

【アルゴリズム 2】拡大モデル (4) を考える. 対 $\left(C_{m}\right.$, $\left.A_{m}\right)$ が可検出であるとする .

(1) $A+\tilde{L}_{x} C$ が安定で , $\left(\bar{H} C_{m}, \bar{A}\right)$ が可検出であるよ うに $\tilde{L}_{x}$ を選ぶ .ここで, $\bar{H}=H\left(I+C \Phi^{-1} \tilde{L}_{x}\right)$ で， $\bar{A}=A_{m}+\left[\tilde{L}_{x}^{\mathrm{T}} 0\right]^{\mathrm{T}} C_{m}$ である.

(2) $\bar{A}+\bar{L} \bar{H} C_{m}$ が安定であるように $\bar{L}\left(\bar{L}=\left[\bar{L}_{x}^{\mathrm{T}} \bar{L}_{d}^{\mathrm{T}}\right]^{\mathrm{T}}\right)$ を選ぶ。

(3) 最終的に , オブザーバゲイン $L$ を

$$
L=\left[\begin{array}{c}
\tilde{L}_{x} \\
0
\end{array}\right]+\left[\begin{array}{c}
\bar{L}_{x} \\
\bar{L}_{d}
\end{array}\right] \bar{H}
$$

と選ぶ。

\section{4. シミュレーション}

アルゴリズムの有効性を検証するため，プラントが 非線形システムである 2 連結タンクシステムを用いて， モデル誤差を想定したシミュレーションを行う . シミュ レーションは, 一般のパーソナルコンピュータ (Pentium $4 \mathrm{CPU}$ 2.60GHz) 上で, AutoGenU[7] (非線形モデル 予測制御のシミュレーションプログラムの自動生成ツー ル) を用いて生成した $\mathrm{C}$ 言語のプログラムで行った .

\section{1 問題設定}

Fig. 2 で表されるような 2 連結タンク系を考える $[8]$.

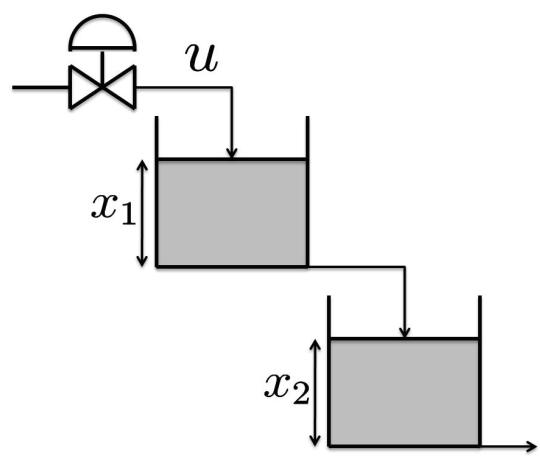

Fig. 2 Tank system

システムは非線形状態方程式

$$
\begin{aligned}
& \dot{x}_{1}(t)=-c_{1} \sqrt{x}_{1}+c_{0} u \\
& \dot{x}_{2}(t)=c_{3} \sqrt{x}_{1}-c_{2} \sqrt{x}_{2}
\end{aligned}
$$

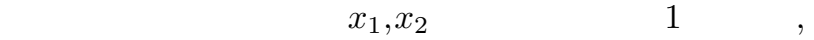
第 2 タンクの液レベル $[\mathrm{m}], u$ は第 1 タンクへの流入 量 $\left[\mathrm{m}^{3} / \mathrm{s}\right]$ である.また， $c_{0}, c_{1}, c_{2}, c_{3}$ はタンクの 断面積や流出口の抵抗などにより決まる定数であり， $c_{0}=1, c_{1}=c_{2}=c_{3}=0.02$ とする. 入力の拘束条件とし て $0 \leq u \leq 0.030$ か課されるものとする .

平衡点を $\left(x_{10}, x_{20}, u_{0}\right)$ とし, 平衡点近傍で非線形状 態方程式 (37),(38) を線形化すると，

$$
\left[\begin{array}{l}
\Delta \dot{x}_{1} \\
\Delta \dot{x}_{2}
\end{array}\right]=\left[\begin{array}{cc}
-\frac{c_{1}}{2 \sqrt{x_{10}}} & 0 \\
\frac{c_{3}}{2 \sqrt{x_{10}}} & -\frac{c_{2}}{2 \sqrt{x_{20}}}
\end{array}\right]\left[\begin{array}{l}
\Delta x_{1} \\
\Delta x_{2}
\end{array}\right]+\left[\begin{array}{c}
c_{0} \\
0
\end{array}\right] \Delta u
$$

となる.ここで, $\Delta x_{1}=x_{1}-x_{10}, \Delta x_{2}=x_{2}-x_{20}, \Delta u=$ $u ー u_{0}$ とおいた . 線形化されたシステム $(39)$ は偏差系 であり，非線形システム $(37),(38)$ も偏差系に直すと，

$$
\begin{aligned}
& \Delta \dot{x}_{1}=-0.02 \sqrt{x_{10}+\Delta x_{1}}+\left(u_{0}+\Delta u\right) \\
& \Delta \dot{x}_{2}=0.02 \sqrt{x_{10}+\Delta x_{1}}-0.02 \sqrt{x_{20}+\Delta x_{2}}
\end{aligned}
$$

となる . 今後, 偏差系を考え, 状態方程式 (40),(41) で 表される非線形プラントに対し，線形化モデル (39)を用 いて推定と制御入力計算を行うものとする.さらに，モ デルのパラメータのうち,$c_{1}$ と $c_{3}$ がプラントの值より 10 \%大きいことを想定し , $c_{1}^{\prime}=c_{2}^{\prime}=0.022$ とする .

\section{2 シミュレーション結果}

ここでは,第 2 タンクの液レベル $x_{2}\left(\Delta x_{2}\right)$ のみ に目標値 $r(t)$ を与え, 光の目標值に定常偏差なく 追従することを要求する.平衡点を $\left(x_{10}, x_{20}, u_{0}\right)=$ $(1.3,1.573,0.022 \sqrt{1.3})$,初期状態を $\left[\Delta x_{1} \Delta x_{2}\right]^{\mathrm{T}}=[-0.2$ $-0.2]^{\mathrm{T}}$ とした .ここで, 平衡点はミスマッチモデルから計 算したものであり，真のプラントの平衡点 $\left(x_{10 p}, x_{20 p}, u_{0 p}\right)$ $=(1.3,1.3,0.02 \sqrt{1.3})$ とは異なることに注意する.さ らに， $\Delta x_{2}$ の目標值を 0.1 と設定した . 目標值は平衡点 から少しずれた值であることに注意する . また , シミュ レーションのパラメータは Table 1のように設定した .

Table 1 Simulation parameters of the tank system

\begin{tabular}{|c|c|c|}
\hline パラメータの説明 & 記号 & 值 \\
\hline \hline 状態の重み & $Q$ & $\operatorname{diag}[0.11]$ \\
\hline 入力の重み & $R$ & 100 \\
\hline 評価区間の長さ & $T$ & $1[\mathrm{~s}]$ \\
\hline サンプリング周期 $(t$ 軸 $)$ & $\Delta t$ & $0.01[\mathrm{~s}]$ \\
\hline サンプリング周期 $(\tau$ 軸 $)$ & $\Delta \tau$ & $0.1[\mathrm{~s}]$ \\
\hline
\end{tabular}

Fig. 3 が兴のシミュレーション結果である $. n_{d}=1$ の 外乱モデルを導入し，拡大モデル $(4)$ における $B_{d}, C_{d}$ は

$$
B_{d}=\left[\begin{array}{l}
10 \\
10
\end{array}\right], \quad C_{d}=\left[\begin{array}{l}
0 \\
0
\end{array}\right]
$$

とした . アルゴリズム 2 を用いて求めたオブザーバゲイ 
ン $L_{1}$ と，同じ外乱モデルを導入したうえで，オブザー バゲインを，Riccati 方程式の重みを単位行列とした定 常カルマンフィルタの解 $L_{2}$ としたものを比較した . こ こで，アルゴリズム 2 において， $\tilde{L}_{x}, \bar{L}$ は単位行列を重 みとした定常カルマンフィルタの解とした . $L_{1}, L_{2}$ の 值は，乥れ次のように得られた。

$$
\begin{aligned}
L_{1} & =\left[\begin{array}{ll}
-10.421 & -47.112 \\
-10.026 & -51.048 \\
-9.784 & -48.872
\end{array}\right] \\
L_{2} & =\left[\begin{array}{ll}
-3.1918 & -2.2105 \\
-2.2105 & -3.2022 \\
-0.70678 & -0.70744
\end{array}\right]
\end{aligned}
$$
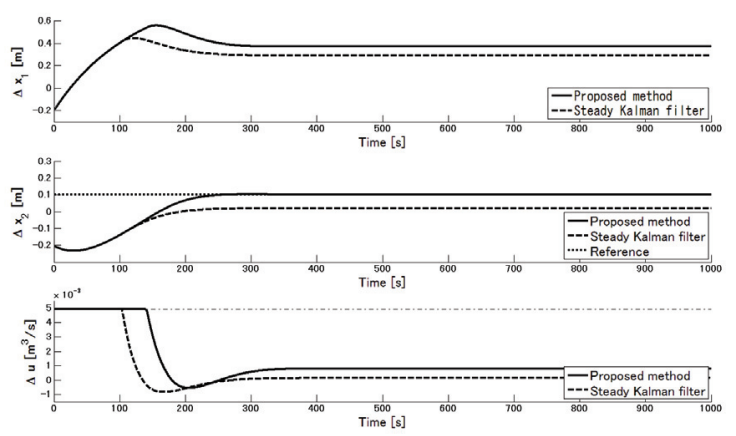

Fig. 3 Simulation result of the tank system (deviation system)

Fig. 3 において，上段と中段のグラフは，弚れ光れ偏 差系における第 1 タンクの液レベル $\Delta x_{1}$ ，第 2 タンク の液レベル $\Delta x_{2}$ をプロットしたものであり，アルゴリ ズムを用いたシミュレーション結果を実線で，定常カル マンフィルタの解を用いたシミュレーション結果を破線 で示している．また，中段のグラフにおける点線は目標 值を表す . 定常カルマンフィルタゲインの方が定常偏差 を示しているのに対し，提案アルゴリズムでシミュレー ションした方は，定常偏差か除去できていることが確認 できる. $\Delta x_{1}$ に関しては，目標値を陽に与えていない が, $\operatorname{SSTO}(18)$ 式から計算された值が目標値となり，評 価関数に組み込まれるため, 発散することなくある一定 值に収束していることに注意する．下段のグラフは偏差 系への入力 $\Delta u$ であり，拘束の上限を一点鎖線で示して いる.拘束の下限はグラフの範囲外のため示していない .

\section{5. おわりに}

本研究は Maeder らの離散時間 MPC における定常偏 差除去理論を連続時間に拡張することを目的とした . ま ず，仮想外乱をモデルに付加した拡大モデルを定義し， 弚れに基づいてオブザーバを設計した . オブザーバで推 定された仮想外乱により MPC における状態と入力の目 標值が修正される . また, 状態と外乱の推定值は MPC を初期化するためにも用いられる。
つぎに, 導入する仮想外乱の次元がシステムの出力の 次元より少ない場合の定常偏差の特徵付けを行い, 制御 出力が定常偏差ゼロとなるための十分条件を導いた . 光 して，弚の条件を満たすオブザーバゲインを求めるアル ゴリズムを提案した .

最後に，提案アルゴリズムを用いたシミュレーション を行い，実際に定常偏差がゼロとなることを確認した . とくに，非線形システムにおいても，線形化を行うこと で本論文の結果が適用できることを示した . 本研究では， モデルプラントミスマッチによる定常偏差を除去するた め，外乱モデルとして一定外乱を採用した . 弚のため， プラントに一定の外乱が加わっている場合にも定常偏差 を除去することができる .一方, 一定でない外乱が加わ る場合は, MPC が本来持つ外乱除去特性によりある程 度の外乱抑制が期待できるが, SSTO が外乱の影響を多 少受けるため，定量的な評価は今後の課題である．

提案アルゴリズムを用いることにより，制御出力のう ち偏差なし追従が要求される出力に対して, 定常偏差を 除去することができた . しかし, 他の制御出力の定常偏 差がアルゴリズムを適用しない場合と比べて大きくなっ てしまうことがある .この点についてさらに考察する必 要がある．また本研究では，参照信号が一定值であるこ とを仮定したが，参照信号がランプ信号や正弦波信号な どの場合でも定常偏差なしで追従できるように , 外乱モ デルを一般化することが考えられる .

\section{参考文献}

[1] J. M. Maciejowski : モデル予測制御 制約のもとでの最 適制御，東京電機大学出版局 (2005)

[2] 大塚 : 非線形 Receding Horizon 制御の計算方法につい て ; 計測と制御，41 巻，5号，pp. 366-371 (2002)

[3] T. Ohtsuka: A continuation/GMRES method for fast computation of nonlinear receding horizon control; Automatica, Vol. 40, No. 4, pp. 563-574 (2004)

[4] G. Pannocchia and J. B. Rawlings: Disturbance models for offset-free model-predictive control; AIChE Journal, Vol. 49, No. 2, pp. 426-437 (2003)

[5] U. Maeder and M. Morari: Linear offset-free model predictive control; Automatica, Vol. 45, No. 10, pp. 2214-2222 (2009)

[6] U. Maeder and M. Morari: Offset-free reference tracking for predictive controllers; Proceedings of the 46th IEEE Conference on Decision and Control, pp. 52525257 (2007)

[7] T. Ohtsuka: AutoGenU, http://www-sc.sys.es.osakau.ac.jp/ ohtsuka/code/index_j.htm (2000)

[8] 竹川, 青木 , 仲矢, 大谷, 大塚 : C/GMRES 法に基づく 非線形モデル予測制御のスタートアップ方法 ; 第 10 回計 測自動制御学会制御部門大会，172-1-5 (2010) 


\section{著者略歴}

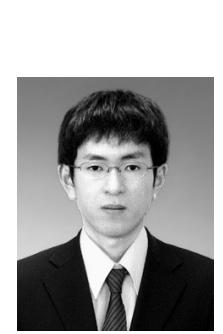

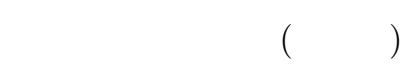

2011 年 3 月大阪大学基礎工学部システ 么科学科卒業, 同年 4 月同大学大学院基礎 工学研究科システム創成専攻博士前期課程 に進学し, 現在に至る. 